\title{
Controversies and discrepancies in the effect of dietary fat and cholesterol on cardiovascular risk
}

\author{
Whye Yi Audrey Leong${ }^{1}$, BSc(Hons), Jinghao Nicholas $\underline{\text { Ngiam}}^{2}$, MBBS, Ru San $\underline{\operatorname{Tan}}^{3}$, MBBS, MRCP, Su Lin $\underline{\operatorname{Lim}}^{4}$, PhD,
}

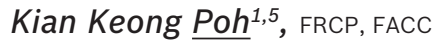

\begin{abstract}
Cardiovascular disease (CVD) is the leading cause of death worldwide. The top ten causes of death in Singapore include many cardiovascular-related diseases such as ischaemic heart disease. The increasing prevalence of CVD poses a burden to both the economy and healthcare system of a country. Dietary habits, in particular dietary fats and cholesterol intake, have been shown to greatly influence CVD risks. Therefore, reference and adherence to relevant dietary guidelines could be crucial in CVD prevention. Recent research findings have provided novel insights into the relationship between certain dietary fats or cholesterol intake and CVD risks, challenging or reinforcing previous guidelines. These findings may, however, be conflicting, and there are still controversies over the effects of dietary fats and cholesterol as well as their association with cardiovascular risk. This review paper aims to evaluate common controversies, identify gaps in relevant research areas and summarise evidence-based dietary recommendations.
\end{abstract}

Keywords: cardiovascular risks, cholesterol, dietary fat, heart disease

\section{INTRODUCTION}

Cardiovascular disease (CVD) is the leading cause of death worldwide, contributing to $31 \%$ of all deaths. ${ }^{(1)}$ The annual number of deaths caused by CVD is expected to rise, from the estimated 17.3 million to 23.6 million by $2030 .{ }^{(2)}$ In Singapore, ischaemic heart disease was the third most common cause of death in 2016. Other CVDs such as cerebrovascular disease and hypertensive heart disease are also among Singapore's top ten causes of death. ${ }^{(3)}$ This increasing prevalence of CVD poses a burden to both the economy and healthcare system of a country.

Numerous studies have demonstrated the significant impact of dietary habits on CVD risks. However, these findings have been conflicting at times, especially for dietary fats and cholesterol intake. ${ }^{(4)}$ Therefore, it is crucial to review dietary guidelines for such nutrients, ensuring the availability of updated information to the public. Such guidelines serve as a reference for healthcare workers and assist policymakers as they tailor-make public health strategies. This review paper aims to consolidate and evaluate some common controversial matters with respect to dietary fats and cholesterol in association with cardiovascular risk, identify gaps in relevant research areas and summarise dietary recommendations based on evidence from research studies.

\section{IS EGG CONSUMPTION ASSOCIATED WITH INCREASED CARDIOVASCULAR RISK?}

Historically, it has been assumed that serum cholesterol levels rise with dietary cholesterol, and that CVD risk would consequently rise with increased dietary cholesterol intake. ${ }^{(5)}$ Therefore, the Singapore Heart Foundation (SHF) recommends a 300-mg limit of dietary cholesterol per day ${ }^{(6)}$ The American Heart Association also sets an upper limit of 300 mg dietary cholesterol per day and intake of three egg yolks per week. ${ }^{(5)}$

More recently, it was consistently demonstrated that this premise is untrue. The latest 2015-2020 American dietary guidelines removed the upper limits for dietary cholesterol.(7) Multiple cohort studies suggested that dietary cholesterol intake does not significantly affect the incident of CVD risk. ${ }^{(8-11)}$ In cholesterol-feeding studies, it was shown that an addition of $100 \mathrm{mg} /$ day dietary cholesterol would only increase serum cholesterol by $1 \%-3 \%$. This minute increase in serum cholesterol does not necessarily have much impact on CVD risk. ${ }^{(12)}$

Eggs are rich dietary sources of cholesterol (200 mg per egg), and numerous studies have focused their investigations on the association between egg consumption and cardiovascular health. ${ }^{(13)}$ Although the SHF still recommends a limit of 3-5 eggs per week for improved heart health, a recent dose-response metaanalysis of six prospective cohort studies actually demonstrated that consuming up to seven eggs per week would not increase cardiovascular risk. ${ }^{(6,13)}$ In another recent randomised, controlled, single-blinded, crossover trial involving 32 adults with coronary artery disease (average age 67 years), no differences were observed in cardiac risk factors, such as serum cholesterol, lipid profile and endothelial function, among three treatment groups (two eggs daily, an egg substitute daily, or no eggs but a high-carbohydrate breakfast daily) over the span of six weeks with a four-week washout period in between each meal plan. ${ }^{(14)}$ However, it was shown in some studies that egg consumption could impact the CVD risk directly in specific subgroups of patients, such as those with chronic diseases and Type 2 diabetes mellitus. ${ }^{(15)}$ 


\section{Possible mechanisms}

The lack of association between dietary cholesterol and CVD risk might be due to a metabolic feedback mechanism regulating cholesterol homeostasis, such as different intestinal absorption and hepatic cholesterol synthesis rates. ${ }^{(16,17)}$ Endogenous cholesterol synthesis may be suppressed when dietary cholesterol is increased. ${ }^{(18)}$ Nevertheless, cholesterol metabolism varies from individual to individual. In specific subgroups of patients, egg consumption was shown to be directly correlated with cardiovascular risk. ${ }^{(15)}$ These individuals could be 'hyperresponders' (25\% of the population) with differing intestinal absorption and endogenous synthesis rates from the rest, resulting in unusually high circulating low-density lipoprotein (LDL) and high-density lipoprotein (HDL) levels..$^{(19,20)}$

Furthermore, particular attention needs to be paid to people with diabetes mellitus and dietary cholesterol consumption. ${ }^{(21)} \mathrm{A}$ recent meta-analysis suggested that although egg consumption has no effect on CVD risk among healthy people, people with diabetes mellitus have a $69 \%$ greater possibility of experiencing CVD when consuming $\geq 1$ egg per day. ${ }^{(22)}$ In the Health, Ageing and Body Composition Study, diets of adults aged 70-79 years were assessed using a food frequency questionnaire. It was observed that consuming $\geq 3$ eggs per week could increase the risk of Type 2 diabetes mellitus patients having a fivefold incidence of CVD. ${ }^{(23)}$ In an analysis of First National Health and Nutrition Examination Survey data, 349 people with diabetes mellitus, with an age range of 25-75 years (during baseline), showed higher risk of myocardial infarction when consuming $>6$ eggs per week during a 20-year follow-up period. (24)

\section{Evaluation of evidence and our recommendation}

The majority of studies on the association between egg consumption and cardiovascular risk have been observational, and there may have been unadjusted confounders. Some studies observed that men who consumed more eggs had less healthy lifestyles, including increased smoking frequency, less physical activity and less ideal eating habits, such as consuming more red and processed meat or less fruits and vegetables. ${ }^{(25,26)}$ Nevertheless, most studies showed no association between dietary cholesterol and CVD risks, suggesting that dietary cholesterol intake may not be directly linked to serum cholesterol in the general population.

Although there is insufficient evidence of an upper dietary cholesterol limit for the general population, certain populations such as individuals who are 'hyper-responders' and those with Type 2 diabetes mellitus should consider limiting eggs and dietary cholesterol and consider more frequent serum monitoring, as they may be more susceptible to fluctuations in serum lipid levels.

\section{ARE ALL FORMS OF TRANS FAT EQUALLY DETRIMENTAL TO CARDIOVASCULAR RISK?}

Compared to dietary cholesterol, trans fat (TF) limits have been more stringent and evidence based. ${ }^{(27-31)}$ In Singapore, AgriFood and Veterinary Authority of Singapore regulations state that fats and oils used in food manufacturing and preparation or for sale should not exceed 2\% TF. ${ }^{(32)}$ Increased TF intake has been consistently associated with increased cardiovascular risk, including both fatal and non-fatal myocardial infarction. ${ }^{(33,34)}$

\section{Possible mechanisms}

Several studies showed that increased TF intake could affect lipid and lipoprotein profile, resulting in higher LDL cholesterol, total cholesterol-HDL cholesterol ratio and lower HDL cholesterol, all of which are CVD risk factors. ${ }^{(35,36)}$ Trials have suggested that higher dietary TF intake could either raise cholesteryl ester transfer protein (CETP) activity or reduce CETP inhibitor activity, thereby increasing the cholesteryl esters transferred from HDL to LDL. ${ }^{(37)}$ There may also be other postulated mechanisms related to inflammatory pathways, involving interleukin 6 and C-reactive protein. ${ }^{(38-40)}$ These inflammatory markers contribute to all stages of atherosclerosis development and plaque formation..$^{(41-44)}$

Industrial TF (iTF) has also been associated with increased CVD risk compared to ruminant TF (rTF). iTF is from industrially manufactured partially hydrogenated vegetable oil in food sources such as margarine, baked products and deep fried foods. ${ }^{(45)}$ rTF is produced naturally when anaerobic bacteria metabolise polyunsaturated fats (PUFA) in the rumens of ruminants, and is usually found in beef, lamb and dairy products. ${ }^{(46)}$ There has been no convincing association between rTF and CVD risks. ${ }^{(46)}$

\section{Evaluation of evidence and our recommendation}

Evidence suggesting a direct association between total TF or iTF and CVD risks has been consistent but does not apply to rTF. While TF restrictions have been implemented in Singapore, efforts could be focused on improving adherence to the TF intake limit. According to the 2010 National Nutrition Survey, three out of ten Singaporeans still exceed the World Health Organization's recommended TF intake limit. ${ }^{(4)}$ This may be in part due to misleading TF nutrition labels. Even products with labels that indicate 'TF free' may be allowed $<0.5 \mathrm{~g}$ of TF per serving by certain governing bodies such as the United States Food and Drug Administration. ${ }^{(48)}$ With serving sizes being reduced, individuals might end up consuming a considerable amount of TF despite consuming only 'TF free' products. While there has not been any controversy in research findings, the requirements for the 'TF free' label are of concern, as such labels may negatively influence the population's TF intake. Such bans have consistently demonstrated positive results in improving cardiovascular health at a population level. ${ }^{(49)}$

\section{SHOULD WE LIMIT ALL TYPES OF SATURATED FATS?}

Some guidelines have limited saturated fat (SF) intake to up to $10 \%$ of total calories. ${ }^{(50,51)}$ In Singapore, the SHF also recommends that SF intake be less than one-third of total daily fat intake $\approx \approx 10 \%$ daily total calories). ${ }^{(52)}$ However, studies on this topic have produced conflicting results. Early studies from 1986 showed that increased SF intake could lead to higher serum cholesterol levels, raising the risk of coronary heart disease (CHD). ${ }^{(53)}$ Similar results were observed from other studies such as the Honolulu 
Heart Program, Framingham Heart Study and Lipid Research Clinics Prevalence Follow-up Study. ${ }^{(9,54-56)}$

On the other hand, more recent studies demonstrated no significant associations between SF and cardiovascular risk. In 2017, the PURE (Prospective Urban Rural Epidemiology) study showed no significant association between SF intake and risks of major CVD, myocardial infarction and CVD mortality. ${ }^{(57)}$ Higher SF intake was even linked with lower risk of stroke. ${ }^{(57)}$ The differences in these findings may be multifactorial. Older studies had focused on European and North American diets, which already had excessive SFs (20\% of total energy intake). The PURE study instead considered diets of populations from high-income, middleincome and low-income countries. This might provide a more comprehensive analysis and a better reflection on the relationship between SF intake and CVD risks, as SF intake varies significantly (2\%-15\% of total energy intake) among different populations. ${ }^{(57)}$

In addition, a recent meta-analysis involving 21 prospective epidemiologic studies showed no association between SF and CVD/CHD risks. ${ }^{(58)}$ The type of nutrients replacing SFs during SF reduction could also play a crucial role in influencing CVD/CHD risks. ${ }^{(59)}$ CVD risk remained unchanged if SFs were replaced by carbohydrates. ${ }^{(35,60)}$ However, when PUFA replaced SFs, CVD risk was reduced. ${ }^{(61,62)}$ Lower CVD risk might be attributed to not only SF reduction but also the increase in PUFA. ${ }^{(63)}$

\section{Possible mechanisms and specific subtypes}

Not all SFs have the same influence on CVD risks. Different SF chain lengths could result in varying effects on serum cholesterol levels. Consuming long-chain SFs (12:0-18:0) was directly related to CHD, while short- or medium-chain SF intake (4.0-10.0) was not. ${ }^{(64-66)}$

The food source from which the SFs originated may also be of importance. SFs from meat were directly associated with higher CVD risks and SFs from dairy products with lower CVD risks, whereas SFs from butter and plant sources had no effect on CVD risks. ${ }^{(67-72)}$ One underlying mechanism might be the blood-pressurelowering effect of oligopeptides produced when probiotic bacteria hydrolyse milk proteins, which inhibit ACE activity, preventing the conversion of angiotensin I to angiotensin II. ${ }^{(73)}$ Minerals found in milk, such as calcium, potassium and magnesium, may contribute to the reduction in blood pressure as well. ${ }^{(74)}$ SFs from butter may have higher HDL-mediated cholesterol efflux capacity that compensates for any LDL-cholesterol-raising effects from butter, resulting in a neutral association between butter and CVD risks. ${ }^{(75)}$ The main sources of SFs from plants are coconut oil and palm oil. Besides SFs, palm oil also consists of oleic acids (monounsaturated) and linoleic acids (LAs; polyunsaturated), and vitamins A and E (antioxidants), which have cardioprotective properties. ${ }^{(76,77)}$ Although lauric acid (C12:0), the main SF in coconut oil, increases LDL cholesterol the most among other long-chain SFs, it raises HDL cholesterol concentration the most as well, hence reducing the total cholesterolHDL cholesterol ratio. ${ }^{(78,79)}$ These factors might contribute to the lack of association between SF from plant sources and CVD risks.

While increased carbohydrate intake result in lower LDL cholesterol compared to SF intake, it could also lead to lower HDL cholesterol as well as an increase in triglycerides, total cholesterol-
HDL cholesterol ratio and apolipoprotein B-apolipoprotein A1 ratio. ${ }^{(57)}$ This might be one reason for the lack of improvement in CVD risks when carbohydrates replace SFs. The quality and glycaemic index of carbohydrate plays a role in its impact on CVD risks as well. Whole grains, when used to replace SFs, have a more positive effect on CVD risks compared to refined sugars. ${ }^{(59)}$

SF-rich red and processed meats are associated with higher CVD risks in some studies. ${ }^{(80)}$ Various nutrient components of red and processed meats, other than SFs, could have contributed to the increased risks. Higher sodium content in processed meat could raise blood pressure, thereby increasing CVD risks; ${ }^{(81)}$ while nitrates and their derivatives could be associated with oxidative stress, leading to endothelial and vascular dysfunction and hence, raising CVD risks as well. ${ }^{(82)}$ In red meat, heme iron could result in the formation of the highly reactive hydroxyl radical, which plays an important role in LDL cholesterol oxidation. ${ }^{(83)}$ Additionally, heme iron and zinc are directly related to C-reactive protein, an inflammatory marker that may promote atherosclerosis development. ${ }^{(84)}$

\section{Evaluation of evidence and our recommendation}

The association between SFs and CVD risk depends on a number of factors, including the length of the fatty acid chain. Recommendations and limits in the future could target an overall diet change instead of dietary guidelines for SF alone. ${ }^{(85)}$ Dietary SF recommendations could focus on limiting certain SF-rich food sources such as red and processed meat. Consumption of refined carbohydrates to replace SFs during SF reduction should be curtailed. It is reasonable to encourage the replacement of SFs with PUFA intake.

\section{ARE MONOUNSATURATED FATTY ACIDS BENEFICIAL?}

Guidelines on the intake of monounsaturated fatty acids (MUFAs) have been vague and variable. MUFAs have often been estimated to be $15 \%-20 \%$ of energy intake. ${ }^{(86)}$ Some organisations have had no specific recommendations for MUFA intake, while in Singapore, the SHF recommends that total unsaturated fatty acids contribute two-thirds of total daily fat intake, with total daily fat intake not exceeding $30 \%$ of total energy intake. ${ }^{(52,87}$

When MUFA intake is increased to replace excessive SF intake in an isocaloric manner, CAD risks could potentially be lowered by approximately $10 \%{ }^{(88)}$ However, these findings were not consistently demonstrated in all studies. ${ }^{(89,90)}$ The PURE study, a large epidemiological cohort study, found no significant association between MUFA and CVD risk. ${ }^{(57)}$ When comparing the different food sources of MUFA, a recent prospective cohort study showed that only plant-based MUFAs, and not animal-based MUFAs, lower CHD risk significantly. ${ }^{(91)}$ Olive oil, in particular, has been associated with protective cardiovascular benefits. ${ }^{(92)}$

\section{Possible mechanisms}

The CAD risk-lowering effects of MUFA observed when MUFA intake replaces saturated fatty acid (SFA) intake could be due to several possible mechanisms, such as the improvement in serum lipid/lipoprotein profile and lowering of blood pressure. 
Previous studies showed a decrease in LDL and total cholesterol levels when MUFAs replace SFA in diets. ${ }^{(93)}$ MUFA is also better at retaining HDL cholesterol levels than PUFA, when comparing the replacement of SFA with either MUFA or PUFA. In a two-way randomised controlled trial, HDL cholesterol levels were lowered by only $4 \%$ when MUFA replaced SFA in diets, much less than the $14 \% \mathrm{HDL}$ cholesterol reduction observed when PUFA replaced SFA. ${ }^{(94)}$ There would be an overall decrease in the total cholesterol-HDL cholesterol ratio. This favourable change in lipid/lipoprotein profile could potentially lower CVD risks. ${ }^{\left({ }^{9}\right)}$

There is evidence that MUFAs, especially oleic acid in olive oil, show hypotensive effects as well. One possible mechanism could be oleic acid's ability to regulate the structure and composition of lipids and $G$ proteins in cell membrane. This could potentially influence the adrenergic receptor signalling pathway, increasing vasodilatory stimuli (cAMP and protein kinase A) production and limiting vasoconstriction pathways (inositol-trisphosphate, Ca2+, diacylglycerol and Rho kinase). ${ }^{(96,97)}$

\section{Evaluation of evidence and our recommendation}

The PURE study challenged some of the findings from previous studies. Its limitations include the inability to estimate fatty acids found in certain foods from countries such as Malaysia and Zimbabwe. Nevertheless, the merits of the study might outweigh its limitations, as it provided data from a wider range of populations with participants from various demographic backgrounds. ${ }^{(57)}$ As it stands, evidence for the association between MUFA intake and CVD risk remains unclear. Traditional dietary guidelines advocating the benefits of low-fat diets have been based on the assumption from controlled feeding trials that increased dietary fat intake was associated with increased serum cholesterol and that consequently, increased serum cholesterol was associated with increased cardiovascular risk. ${ }^{(98)}$ The large PURE study challenged that fundamental assumption and demonstrated that not all forms of dietary fat were responsible for increasing cardiovascular risk. The CHD risk-lowering effects of plant-based MUFA could be partially contributed by other residual confounding factors, such as dietary fibre, polyphenols and minerals found in plants. Animal-based MUFAs, on the other hand, are often found in food sources such as red meats and dairy products, which are also rich in SFA. ${ }^{(91)}$ Overall, a significant difficulty in designing such dietary studies and guidelines comes from the fact that MUFAs are rarely consumed in isolation. Dietary guidelines could instead focus more on limiting or encouraging the consumption of specific food products and diets, instead of limiting specific nutrients. In the case of MUFAs, dietary fat derived from olive oil may be beneficial compared to those from animal sources.

\section{IS THERE A ROLE FOR N-6/N-3 POLYUNSATURATED FATTY ACIDS IN CARDIOVASCULAR HEALTH?}

PUFAs are a group of fatty acids that were shown to have cardioprotective effects. They mainly comprise n-6 PUFAs such as linoleic acid (LA) and n-3 PUFA. n-3 PUFAs are further classified into plant-derived alpha-linolenic acid (ALA) as well as marine-derived eicosapentaenoic acid (EPA) and docosahexaenoic acid (DHA). ${ }^{(99)}$ Lower CVD risks have been observed among populations that consume more fish, such as Alaska Natives, Greenland Eskimos and the Japanese. Fishes, especially fatty fishes such as salmon and herring, are rich in EPA and DHA, containing up to 2,000 mg EPA and DHA per 100 g. ${ }^{(98,100)}$ The cardiovascular benefits of PUFAs may be mediated by altering the lipid profile, inhibiting inflammation and platelet aggregation. ${ }^{(101-103)}$ Additionally, n-3 PUFAs have been useful in secondary prevention of atherosclerotic cardiovascular disease. Following myocardial infarction, patients with higher PUFA intake (mainly from marine sources) showed significantly lower mortality and less recurrence of cardiovascular events such as myocardial infarction or stroke. ${ }^{(104-107)}$ While EPA and DHA intake (from marine sources) consistently show cardiovascular benefit, plant-based PUFAs (mainly ALA) may also lower cardiovascular risk, but studies on the latter show conflicting findings. ${ }^{(108-110)}$

\section{Possible mechanisms}

The underlying mechanism and conceptual importance of the n-6/n-3 ratio stems from the competitive conversion of ALA to the more bioactive EPA and DHA. However, the enzyme, which is more specific for ALA, may be competitively inhibited by $n-6$ PUFA (dietary LA) if it were in abundance. This would limit the in vivo conversion of ALA to EPA and thus limit its cardioprotective effects. ${ }^{(111,112)} A$ lower $n-6 / n-3$ ratio would thus be beneficial, and dietary strategies have been aimed at decreasing n-6 PUFA while increasing n-3 PUFA.

A large randomised trial, OPTILIP, was designed to examine the optimal $n-6 / n-3$ ratio by comparing diets with an $n-6 / n-3$ PUFA ratio of between 3:1 and 5:1 with a control of 10:1. However, the findings revealed no treatment effects and thus no effect on insulin sensitivity, haemostatic function, plasma postheparin lipase activities or serum lipid profile. ${ }^{(113)}$ The authors postulated that the in vivo conversion of ALA to EPA and DHA may only occur to a limited extent and, therefore, the effect of differing $n-6 / n-3$ ratios may not have been significant. Instead of the ratio, absolute amounts of n-6 PUFA and ALA (n-3 PUFA) may be more important. Goyens et al demonstrated that lowering LA ( $n-6)$ aided in the synthesis of EPA, while increasing ALA promoted the conversion of EPA to DHA. ${ }^{(14)}$

\section{Evaluation of evidence and our recommendation}

The cardioprotective effects of EPA and DHA are supported by strong evidence. ${ }^{(115,116)}$ Fish and marine sources are particularly important for this nutrient. ${ }^{(117)}$ Based on current evidence, the recommended EPA and DHA intake could be approximately 300-600 mg per day for primary prevention of CVD and about 900-1,200 mg per day for secondary prevention. ${ }^{(118)}$ Instead of focusing on the $n-6 / n-3$ ratio, enhanced conversion of ALA to long-chain n-3 PUFAs may instead by achieved by decreasing the absolute amount of dietary LA and increasing the absolute amount of dietary ALA. 


\section{CONCLUSION}

Diet, particularly dietary fats and cholesterol intake, plays an important role in altering CVD risks. Studies on certain nutrients, such as TF, showed strong evidence for increasing CVD risks. However, findings on dietary cholesterol, MUFAs and SFs are still conflicting or unclear. Individual responses to dietary cholesterol should be monitored, as they are often variable. Food sources of dietary fats and cholesterol are also important considerations, and food-based recommendations and restrictions may be more practical than nutrient-specific limits. Instead of the n-6/n-3 PUFA ratio, lowering absolute levels of LA and increasing dietary ALA may be helpful. Overall, appropriately controlling dietary fat and cholesterol consumption may help to lower both the social and economic burden of CVD.

\section{REFERENCES}

1. World Health Organization. Cardiovascular diseases (CVDs). Available at: http:// www.who.int/mediacentre/factsheets/fs317/en/. Accessed August 16, 2017.

2. American Heart Association. New statistical update looks at worldwide heart, stroke health 2014. Available at: http://newsroom. heart.org/news/new-statisticalupdate-looks-at-worldwide-heart-stroke-health. Accessed August 16, 2017.

3. Ministry of Health, Singapore. Principal causes of death. Available at: https:// www.moh.gov.sg/content/moh_web/home/statistics/Health_Facts_Singapore/ Principal_Causes_of_Death.html. Accessed August 16, 2017.

4. Salter AM. Dietary fatty acids and cardiovascular disease. Animal 2012; 7 Suppl $1: 163-71$.

5. Willett W. Nutritional Epidemiology. 2nd ed. New York: Oxford University Press, 1998.

6. Singapore Heart Foundation. Taking less cholesterol. Available at: http://www. myheart.org.sg/article/a-heart-healthy-lifestyle/diet-and-nutrition/taking-lesscholesterol/216. Accessed March 25, 2017.

7. U.S. Department of Agriculture. Dietary guidelines for Americans 2015-2020. 8th ed. Available at: https://health.gov/sites/default/files/2019-09/2015-2020_ Dietary_Guidelines.pdf. Accessed August 16, 2017.

8. Berger S, Raman G, Vishwanathan R, Jacques PF, Johnson EJ. Dietary cholestero and cardiovascular disease: a systematic review and meta-analysis. Am J Clin Nutr 2015; 102:276-94.

9. Posner BM, Cobb JL, Belanger AJ, et al. Dietary lipid predictors of coronary heart disease in men. The Framingham Study. Arch Intern Med 1991; 151:1181-7.

10. Hu FB, Manson JE, Willett WC. Types of dietary fat and risk of coronary heart disease: a critical review. J Am Coll Nutr 2001; 20:5-19.

11. Stanley J. Dietary cholesterol, blood cholesterol and cardiovascular disease. Lipid Technol 2010; 22:110-2.

12. McNamara DJ. The impact of egg limitations on coronary heart disease risk: do the numbers add up? J Am Coll Nutr 2000; 19 (5 Suppl):540S-8S.

13. Ruxton CHS, Derbyshire E, Gibson SA. The nutritional properties and health benefits of eggs. Nutr Food Sci 2010; 40:263-79.

14. Katz DL, Gnanaraj J, Treu JA, et al. Effects of egg ingestion on endothelial function in adults with coronary artery disease: a randomized, controlled, crossover trial. Am Heart J 2015; 169:162-9.

15. Fernandez ML. Effects of eggs on plasma lipoproteins in healthy populations. Food Funct 2010; 1:156-60.

16. Lecerf JM, de Lorgeril M. Dietary cholesterol: from physiology to cardiovascular risk. Br J Nutr 2011; 106:6-14.

17. McNamara DJ, Kolb R, Parker TS, et al. Heterogeneity of cholesterol homeostasis in man. Response to changes in dietary fat quality and cholesterol quantity. J Clin Invest 1987; 79:1729-39.

18. Jones PJ, Pappu AS, Hatcher L, et al. Dietary cholesterol feeding suppresses human cholesterol synthesis measured by deuterium incorporation and urinary mevalonic acid levels. Arterioscler Thromb Vasc Biol 1996; 16:1222-8.

19. Williams KA Sr, Krause AJ, Shearer S, Devries S. The 2015 Dietary Guidelines Advisory Committee Report concerning dietary cholesterol. Am J Cardiol 2015; 116:1479-80.

20. Ostlund RE Jr, Bosner MS, Stenson WF. Cholesterol absorption efficiency declines at moderate dietary doses in normal human subjects. J Lipid Res 1999; 40:1453-8.

21. Fernandez ML, Andersen CJ. Effects of dietary cholesterol in diabetes and cardiovascular disease. Clin Lipidol 2014; 9:607-16.

22. Shin JY, Xun P, Nakamura Y, He K. Egg consumption in relation to risk of cardiovascular disease and diabetes: a systematic review and meta-analysis. Am J Clin Nutr 2013; 98:146-59.

23. Houston DK, Ding J, Lee JS, et al; Health ABC Study. Dietary fat and cholesterol and risk of cardiovascular disease in older adults: the Health ABC Study. Nutr Metab Cardiovasc Dis 2011; 21:430-7.

24. Qureshi Al, Suri FK, Ahmed S, et al. Regular egg consumption does not increase the risk of stroke and cardiovascular diseases. Med Sci Monit 2007; 13:CR1-8.

25. Hu FB, Stampfer MJ, Rimm EB, et al. A prospective study of egg consumption and risk of cardiovascular disease in men and women. JAMA 1999; 281:1387-94.

26. Rong Y, Chen L, Zhu T, et al. Egg consumption and risk of coronary heart disease and stroke: dose-response meta-analysis of prospective cohort studies. BMJ 2013; 346:e8539.

27. Restrepo BJ, Rieger M. Denmark's policy on artificial trans fat and cardiovascular disease. Am J Prev Med 2016; 50:69-76.

28. U.S. Food and Drug Administration. Final determination regarding partially hydrogenated oils (removing trans fat). Available at: https://www.fda.gov/Food/ IngredientsPackagingLabeling/FoodAdditivesIngredients/ucm449162.htm. Accessed June 4, 2018

29. World Health Organization. WHO plan to eliminate industrially-produced transfatty acids from global food supply. 14 May 2018. Available at: https://www. who.int/news-room/detail/14-05-2018-who-plan-to-eliminate-industriallyproduced-trans-fatty-acids-from-global-food-supply. Accessed June 4, 2018.

30. Food and Drug Administration, HHS. Food Labeling: trans fatty acids in nutrition labeling, nutrient content claims, and health claims. Final rule. Fed Regist 2003; 68:41433-1506.

31. Nishida C, Uauy R. WHO Scientific Update on health consequences of trans fatty acids: introduction. Eur J Clin Nutr 2009; 63 Suppl 2:S1-4.

32. Agri-Food and Veterinary Authority of Singapore. Sale of Food Act Food Regulations. Available at: https://www.sfa.gov.sg/docs/default-source/legislation/ sale-of-food-act/food_regulations.pdf. Accessed June 4, 2018.

33. Mozaffarian D, Katan MB, Ascherio A, Stampfer MJ, Willett WC. Trans fatty acids and cardiovascular disease. N Engl J Med 2006; 354:1601-13.

34. Oh K, Hu FB, Manson JE, Stampfer MJ, Willett WC. Dietary fat intake and risk of coronary heart disease in women: 20 years of follow-up of the nurses' health study. Am J Epidemiol 2005; 161:672-9.

35. Mensink RP, Zock PL, Kester AD, Katan MB. Effects of dietary fatty acids and carbohydrates on the ratio of serum total to HDL cholesterol and on serum lipids and apolipoproteins: a meta-analysis of 60 controlled trials. Am J Clin Nutr 2003; 77:1146-55

36. Mozaffarian D, Clarke R. Quantitative effects on cardiovascular risk factors and coronary heart disease risk of replacing partially hydrogenated vegetable oils with other fats and oils. Eur J Clin Nutr 2009; 63 Suppl 2:S22-33.

37. van Tol A, Zock PL, van Gent T, Scheek LM, Katan MB. Dietary trans fatty acids increase serum cholesterylester transfer protein activity in man. Atherosclerosis 1995; 115:129-34.

38. Gebauer SK, Baer DJ. Trans-fatty acids: health effects, recommendations, and regulations. In: Allen LH, Prentice A, eds. Encyclopedia of Human Nutrition. 3rd ed. Academic Press, 2013.

39. Lopez-Garcia E, Schulze MB, Meigs JB, et al. Consumption of trans fatty acids is related to plasma biomarkers of inflammation and endothelial dysfunction. J Nutr 2005; 135:562-6.

40. Mozaffarian D, Pischon T, Hankinson SE, et al. Dietary intake of trans fatty acids and systemic inflammation in women. Am J Clin Nutr 2004; 79:606-12.

41. Cesari M, Penninx BW, Newman AB, et al. Inflammatory markers and onset of cardiovascular events: results from the Health $A B C$ study. Circulation 2003; 108:2317-22.

42. Hansson GK, Robertson AK, Söderberg-Nauclér C. Inflammation and atherosclerosis. Annu Rev Pathol 2006; 1:297-329.

43. Baer DJ, Judd JT, Clevidence BA, Tracy RP. Dietary fatty acids affect plasma markers of inflammation in healthy men fed controlled diets: a randomized crossover study. Am J Clin Nutr 2004; 79:969-73.

44. Constans J, Conri C. Circulating markers of endothelial function in cardiovascular disease. Clin Chim Acta 2006; 368:33-47.

45. Mozaffarian D, Stampfer MJ. Removing industrial trans fat from foods. BMJ 2010; 340:c1826.

46. Gebauer SK, Chardigny JM, Jakobsen MU, et al. Effects of ruminant trans fatty acids on cardiovascular disease and cancer: a comprehensive review of epidemiological, clinical, and mechanistic studies. Adv Nutr 2011; 2:332-54.

47. Health Promotion Board, Singapore. Industry on track to meet trans fat regulation by May 2013. Available at: https://www.hpb.gov.sg/article/industry-on-trackto-meet-trans-fat-regulation-by-may-2013. Accessed June 6, 2017.

48. U.S. Food and Drug Administration. Small entity compliance guide: trans fatty acids in nutrition labeling, nutrient content claims, and health claims. August 2003. Available at: https://www.fda.gov/Food/GuidanceRegulation/ GuidanceDocumentsRegulatoryInformation/LabelingNutrition/ucm053479. htm. Accessed June 4, 2018.

49. Restrepo BJ, Rieger M. Trans fat and cardiovascular disease mortality: evidence from bans in restaurants in New York. J Health Econ 2016; 45:176-96.

50. US Department of Health and Human Services, US Department of Agriculture. Dietary Guidelines for Americans 2015-2020 Eight Edition. Available at: http:// health.gov/dietaryguidelines/2015/guidelines/. Accessed June 4, 2018.

51. Food Standards Agency, UK. FSA nutrient and food based guidelines for 
UK institutions. Revised October 2007. Available at: https://www.ptdirect. com/training-design/nutrition/national-nutrition-guidelines-united-kingdom. Accessed June 4, 2018.

52. Singapore Heart Foundation. Limiting Fat Intake. 2012. Available at: http:// www.myheart.org.sg/article/a-heart-healthy-lifestyle/diet-and-nutrition/limitingfat-intake/215. Accessed June 4, 2018.

53. Ascherio A, Rimm EB, Giovannucci EL, et al. Dietary fat and risk of coronary heart disease in men: cohort follow up study in the United States. BMJ 1996; 313:84-90.

54. McGee DL, Reed DM, Yano K, Kagan A, Tillotson J. Ten-year incidence of coronary heart disease in the Honolulu Heart Program. Relationship to nutrient intake. Am J Epidemiol 1984; 119:667-76.

55. Esrey KL, Joseph L, Grover SA. Relationship between dietary intake and coronary heart disease mortality: lipid research clinics prevalence follow-up study. J Clin Epidemiol 1996; 49:211-6.

56. Hooper L, Summerbell CD, Thompson R, et al. Reduced or modified dietary fat for preventing cardiovascular disease. Sao Paulo Med J 2016; 134:182-3.

57. Dehghan M, Mente A, Zhang X, et al. Associations of fats and carbohydrate intake with cardiovascular disease and mortality in 18 countries from five continents (PURE): a prospective cohort study. Lancet 2017; 390:2050-62.

58. Siri-Tarino PW, Sun Q, Hu FB, Krauss RM. Meta-analysis of prospective cohort studies evaluating the association of saturated fat with cardiovascular disease. Am J Clin Nutr 2010; 91:535-46.

59. Li YP, Hruby A, Bernstein AM, et al. Saturated fats compared with unsaturated fats and sources of carbohydrates in relation to risk of coronary heart disease: a prospective cohort study. J Am Coll Cardiol 2015; 66:1538-48.

60. Siri-Tarino PW, Chiu S, Bergeron N, Krauss RM. Saturated fats versus polyunsaturated fats versus carbohydrates for cardiovascular disease prevention and treatment. Annu Rev Nutr 2015; 35:517-43.

61. Hu FB, Stampfer MJ, Manson JE, et al. Dietary fat intake and the risk of coronary heart disease in women. N Engl J Med 1997; 337:1491-9.

62. Mozaffarian D, Micha R, Wallace S. Effects on coronary heart disease of increasing polyunsaturated fat in place of saturated fat: a systematic review and meta-analysis of randomized controlled trials. PLoS Med 2010; 7:e1000252.

63. Virtanen JK. Dietary polyunsaturated fat intake in coronary heart disease risk. Clinical Lipidology 2015; 10:115-7.

64. Hu FB, Stampfer MJ, Manson JE, et al. Dietary saturated fats and their food sources in relation to the risk of coronary heart disease in women. Am J Clin Nutr 1999; 70:1001-8.

65. Yu S, Derr J, Etherton TD, Kris-Etherton PM. Plasma cholesterol-predictive equations demonstrate that stearic acid is neutral and monounsaturated fatty acids are hypocholesterolemic. Am J Clin Nutr 1995; 61:1129-39.

66. Mensink RP, Katan MB. Effect of dietary fatty acids on serum lipids and lipoproteins. A meta-analysis of 27 trials. Arterioscler Thromb 1992; 12:911-9.

67. de Oliveira Otto MC, Mozaffarian D, Kromhout D, et al. Dietary intake of saturated fat by food source and incident cardiovascular disease: the MultiEthnic Study of Atherosclerosis. Am J Clin Nutr 2012; 96:397-404.

68. O'Sullivan TA, Hafekost K, Mitrou F, Lawrence D. Food sources of saturated fat and the association with mortality: a meta-analysis. Am J Public Health 2013; 103:e31-42.

69. Benatar JR, Stewart RA. The effects of changing dairy intake on trans and saturated fatty acid levels- results from a randomized controlled study. Nutr J 2014; 13:32.

70. Gibson RA, Makrides M, Smithers LG, Voevodin M, Sinclair AJ. The effect of dairy foods on CHD: a systematic review of prospective cohort studies. $\mathrm{Br}$ Nutr 2009; 102:1267-75

71. Soedamah-Muthu SS, Ding EL, Al-Delaimy WK, et al. Milk and dairy consumption and incidence of cardiovascular diseases and all-cause mortality: dose-response meta-analysis of prospective cohort studies. Am J Clin Nutr 2011; 93:158-71.

72. Alexander DD, Bylsma LC, Vargas AJ, et al. Dairy consumption and CVD: a systematic review and meta-analysis. Br J Nutr 2016; 115:737-50.

73. Ebringer L, Ferencík M, Krajcovic J. Beneficial health effects of milk and fermented dairy products--review. Folia Microbiol (Praha) 2008; 53:378-94.

74. Houston MC, Harper KJ. Potassium, magnesium, and calcium: their role in both the cause and treatment of hypertension. J Clin Hypertens (Greenwich) 2008 ; 10(7 Suppl 2):3-11.

75. Brassard D, Arsenault BJ, Boyer M, et al. Saturated fats from butter but not from cheese increase HDL-mediated cholesterol efflux capacity from $\mathbf{7 7 7 4}$ macrophages in men and women with abdominal obesity. J Nutr 2018; 148:573-80.

76. Odia OJ, Ofori S, Maduka O. Palm oil and the heart: a review. World J Cardiol 2015; 7:144-9.

77. Ismail SR, Maarof SK, Siedar Ali S, Ali A. Systematic review of palm oil consumption and the risk of cardiovascular disease. PLoS One 2018; 13:e0193533.

78. Briggs MA, Petersen KS, Kris-Etherton PM. Saturated fatty acids and cardiovascular disease: replacements for saturated fat to reduce cardiovascular risk. Healthcare (Basel) 2017; 5. pii:E29.

79. Khaw KT, Sharp SJ, Finikarides L, et al. Randomised trial of coconut oil, olive oil or butter on blood lipids and other cardiovascular risk factors in healthy men and women. BMJ Open 2018; 8:e020167.

80. Micha R, Wallace SK, Mozaffarian D. Red and processed meat consumption and risk of incident coronary heart disease, stroke, and diabetes mellitus: a systematic review and meta-analysis. Circulation 2010; 121:2271-83.

81. Sacks FM, Svetkey LP, Vollmer WM, et al; DASH-Sodium Collaborative Research Group. Effects on blood pressure of reduced dietary sodium and the Dietary Approaches to Stop Hypertension (DASH) diet. N Engl J Med 2001; 344:3-10.

82. Förstermann U. Oxidative stress in vascular disease: causes, defense mechanisms and potential therapies. Nat Clin Pract Cardiovasc Med 2008; 5:338-49.

83. Tappel A. Heme of consumed red meat can act as a catalyst of oxidative damage and could initiate colon, breast and prostate cancers, heart disease and other diseases. Med Hypotheses 2007; 68:562-4.

84. de Oliveira Otto MC, Alonso A, Lee DH, et al. Dietary micronutrient intakes are associated with markers of inflammation but not with markers of subclinical atherosclerosis. J Nutr 2011; 141:1508-15.

85. O'Connor A. Study doubts saturated fat's link to heart disease. New York Times. 2014 March 18.

86. Food and Agriculture Organization. Interim summary of conclusions and dietary recommendations on total fat and fatty acids. 2010. Available at: http://www. fao.org/ag/agn/nutrition/docs/Fats\%20and\%20Fatty\%20Acids\%20Summary. pdf. Accessed June 4, 2018.

87. EFSA Panel on Dietetic Products, Nutrition, and Allergies (NDA). Scientific opinion on dietary reference values for fats, including saturated fatty acids, polyunsaturated fatty acids, monounsaturated fatty acids, trans fatty acids, and cholesterol. EFSA J 2010; 8:1461.

88. Berglund L, Lefevre M, Ginsberg HN, et al; DELTA Investigators. Comparison of monounsaturated fat with carbohydrates as a replacement for saturated fat in subjects with a high metabolic risk profile: studies in the fasting and postprandial states. Am J Clin Nutr 2007; 86:1611-20.

89. de Souza RJ, Mente A, Maroleanu A, et al. Intake of saturated and trans unsaturated fatty acids and risk of all cause mortality, cardiovascular disease, and type 2 diabetes: systematic review and meta-analysis of observational studies. BMJ 2015; 351:h3978.

90. Jakobsen $\mathrm{MU}, \mathrm{O}^{\prime}$ Reilly EJ, Heitmann BL, et al. Major types of dietary fat and risk of coronary heart disease: a pooled analysis of 11 cohort studies. Am J Clin Nutr 2009; 89:1425-32.

91. Zong G, Li Y, Sampson L, et al. Monounsaturated fats from plant and animal sources in relation to risk of coronary heart disease among US men and women. Am J Clin Nutr 2018; 107:445-53.

92. Schwingshackl L, Hoffmann G. Monounsaturated fatty acids, olive oil and health status: a systematic review and meta-analysis of cohort studies. Lipids Health Dis $2014 ; 13: 154$.

93. Mensink RP. Effects of saturated fatty acids on serum lipids and lipoproteins: a systematic review and regression analysis. Available at: https://apps. who.int/iris/bitstream/handle/10665/246104/9789241565349-eng. pdf;jsessionid=E89720005A904C449AA2A6A62D8FC021. Accessed April 13, 2020

94. Hodson L, Skeaff CM, Chisholm WA. The effect of replacing dietary saturated fat with polyunsaturated or monounsaturated fat on plasma lipids in free-living young adults. Eur J Clin Nutr 2001; 55:908-15.

95. Gillingham LG, Harris-Janz S, Jones PJ. Dietary monounsaturated fatty acids are protective against metabolic syndrome and cardiovascular disease risk factors. Lipids 2011; 46:209-28

96. Qian F, Korat AA, Malik V, Hu FB. Metabolic effects of monounsaturated fatty acid-enriched diets compared with carbohydrate or polyunsaturated fatty acid-enriched diets in patients with type 2 diabetes: a systematic review and meta-analysis of randomized controlled trials. Diabetes Care 2016; 39:1448-57.

97. Terés S, Barceló-Coblijn G, Benet M, et al. Oleic acid content is responsible for the reduction in blood pressure induced by olive oil. Proc Natl Acad Sci U S A 2008; 105:13811-6.

98. Liu AG, Ford NA, Hu FB, et al. A healthy approach to dietary fats: understanding the science and taking action to reduce consumer confusion. Nutr J 2017; 16:53.

99. Flock MR, Harris WS, Kris-Etherton PM. Long-chain omega-3 fatty acids: time to establish a dietary reference intake. Nutr Rev 2013; 71:692-707.

100. Hu FB, Cho EY, Rexrode KM, Albert CM, Manson JE. Fish and long-chain omega-3 fatty acid intake and risk of coronary heart disease and total mortality in diabetic women. Circulation 2003; 107:1852-7.

101. Adkins Y, Kelley DS. Mechanisms underlying the cardioprotective effects of omega-3 polyunsaturated fatty acids. J Nutr Biochem 2010; 21:781-92.

102. Jump DB, Depner CM, Tripathy S. Omega-3 fatty acid supplementation and cardiovascular disease. Thematic review series: new lipid and lipoprotein targets for the treatment of cardiometabolic diseases. J Lipid Res 2012; 53:2525-45.

103. Dewailly E, Blanchet C, Lemieux S, et al. n-3 fatty acids and cardiovascular disease risk factors among the Inuit of Nunavik. Am J Clin Nutr 2001; 74:464-73.

104. Dietary supplementation with $\mathrm{n}-3$ polyunsaturated fatty acids and vitamin $\mathrm{E}$ after myocardial infarction: results of the GISSI-Prevenzione trial. Lancet 1999; $354: 447-55$

105. Kromhout D, Giltay EJ, Geleijnse JM; Alpha Omega Trial Group. n-3 fatty acids 
and cardiovascular events after myocardial infarction. N Engl J Med 2010; 363:2015-26.

106. Osler M, Andreasen AH, Hoidrup S. No inverse association between fish consumption and risk of death from all-causes, and incidence of coronary heart disease in middle-aged, Danish adults. J Clin Epidemiol 2003; 56:274-9.

107. Burr ML, Fehily AM, Gilbert JF, et al. Effects of changes in fat, fish, and fibre intakes on death and myocardial reinfarction: diet and reinfarction trial (DART). Lancet $1989 ; 2: 757-61$.

108. Wang C, Harris WS, Chung M, et al. n-3 fatty acids from fish or fish-oil supplements, but not alpha-linolenic acid, benefit cardiovascular disease outcomes in primary- and secondary-prevention studies: a systematic review. Am J Clin Nutr 2006; 84:5-17.

109. Fleming JA, Kris-Etherton PM. The evidence for $\alpha$-linolenic acid and cardiovascular disease benefits: comparisons with eicosapentaenoic acid and docosahexaenoic acid. Adv Nutr 2014; 5:863S-76S.

110. Pan A, Chen M, Chowdhury R, et al. $\alpha$-linolenic acid and risk of cardiovascular disease: a systematic review and meta-analysis. Am J Clin Nutr 2012; 96:1262-73.

111. Burdge GC, Calder PC. $\alpha$-linolenic acid metabolism in adult humans: the effects of gender and age on conversion to longer-chain polyunsaturated fatty acids. Eur J Lipid Sci Tech 2005; 107:426-39.

112. Burdge GC, Calder PC. Conversion of alpha-linolenic acid to longer-chain polyunsaturated fatty acids in human adults. Reprod Nutr Dev 2005; 45:581-97.
113. Sanders TA, Lewis F, Slaughter S, et al. Effect of varying the ratio of n-6 to n-3 fatty acids by increasing the dietary intake of alpha-linolenic acid, eicosapentaenoic and docosahexaenoic acid, or both on fibrinogen and clotting factors VII and XII in persons aged 45-70 y: the OPTILIP study. Am J Clin Nutr 2006; 84:513-22.

114. Goyens PL, Spilker ME, Zock PL, Katan MB, Mensink RP. Conversion of alpha-linolenic acid in humans is influenced by the absolute amounts of alpha-linolenic acid and linoleic acid in the diet and not by their ratio. Am J Clin Nutr 2006; 84:44-53.

115. Plourde M, Cunnane SC. Extremely limited synthesis of long chain polyunsaturates in adults: implications for their dietary essentiality and use as supplements. Appl Physiol Nutr Metab 2007; 32:619-34.

116. Brenna JT. Efficiency of conversion of alpha-linolenic acid to long chain n-3 fatty acids in man. Curr Opin Clin Nutr Metab Care 2002; 5:127-32.

117. American Heart Association. Fish and omega-3 fatty acids. Available at: http:// www.heart.org/HEARTORG/HealthyLiving/HealthyEating/HealthyDietGoals/ Fish-and-Omega-3-Fatty-Acids_UCM_303248_Article.jsp. Accessed September 11, 2017.

118. Vrablík M, Prusiková M, Snejdrlová M, Zlatohlávek L. Omega-3 fatty acids and cardiovascular disease risk: do we understand the relationship? Physiol Res 2009; 58 Suppl 1:S19-26.

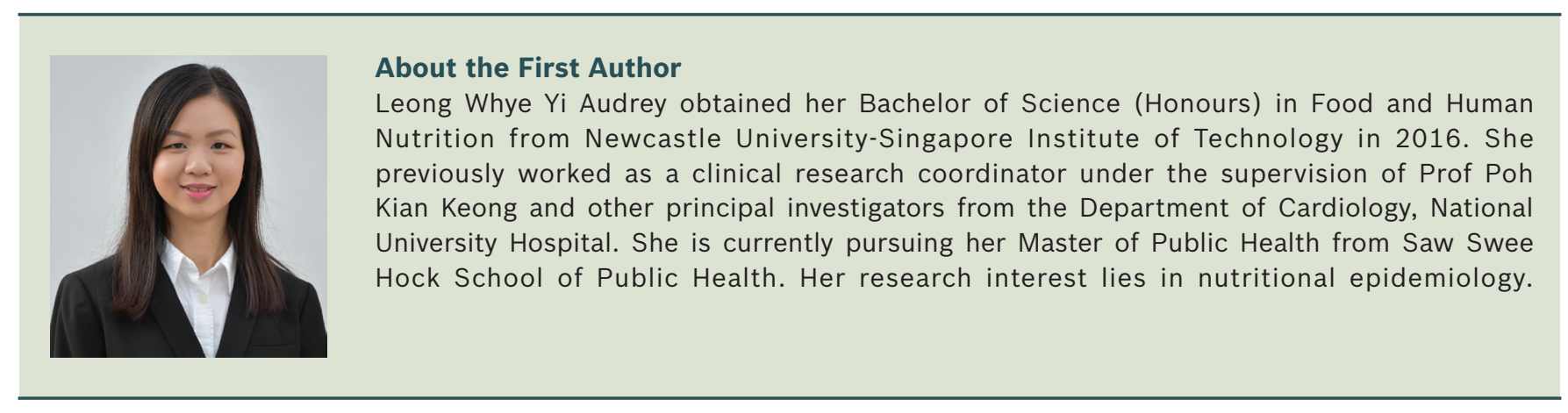

